\title{
An Estimate of the Geosat Altimeter Wind Speed Algorithm at High Wind Speeds
}

\author{
IAN R. YOUNG \\ Department of Civil and Maritime Engineering, University College, \\ University of New South Wales, Canberra, A.C.T., Australia
}

\begin{abstract}
Existing wind speed algorithms for satellite altimeters have been developed from data in the range 0 to $20 \mathrm{~m} / \mathrm{s}$. At higher wind speeds the available algorithms diverge alarmingly. By comparing Geosat altimeter values of the radar cross section with model predictions of the surface winds during satellite overpasses of tropical cyclones, a wind speed algorithm valid for wind speeds between 20 and $40 \mathrm{~m} / \mathrm{s}$ is developed. There is, however, considerable scatter in these data. An error analysis shows that this observed scatter is consistent with the accuracy to which the tropical cyclone wind fields can be inferred. An approximately linear dependence of the radar cross section on wind speed is, however, clearly evident within these data. At the lower limit of its applicability $\left(U_{10}=20 \mathrm{~m} / \mathrm{s}\right)$, these data are consistent with the previously derived algorithms. At its upper limit $\left(U_{10}=40 \mathrm{~m} / \mathrm{s}\right)$, mean squared slope values inferred from the radar cross section are consistent with the theoretical upper limit.
\end{abstract}

\section{INTRODUCTION}

Satellite radar altimeters (ALT) were primarily developed for the measurement of sea surface elevation, from which such properties as the large-scale ocean circulation can be inferred. In addition, they can determine significant wave height quite accurately and wind speed to a lower accuracy [Fedor and Brown, 1982]. Multichannel microwave radiometers (such as SSM/I) can also measure wind speed. They provide a significantly greater spatial coverage than ALT but at poorer spatial resolution. The instrument of choice for the determination of surface wind speeds from an orbiting platform is generally regarded as the scatterometer (SCATT) [Chelton and $M c$ Cabe, 1985]. While there are many years of data and global coverage from a number of ALT missions, SCATT data are still very limited. As a result, a considerable body of work has concentrated on methods for the accurate determination of wind speed from ALT data.

To date, there have been four satellite altimeters from which useful estimates of wind speed could be made. The first of these was GEOS 3, which operated for a period of approximately 3.5 years until December 1978. Seasat had both ALT and SCATT but operated for the relatively short period from July 1978 until October 1978. The most comprehensive high-quality ALT data available to date were provided by Geosat, which operated from March 1985 until September 1989. Recently (July 1991), ERS 1, which carries both ALT and SCATT, has been launched.

A number of different algorithms have been proposed for the determination of wind speed from the radar cross section $\sigma_{0}$ (see section 2). A variety of techniques have been used to derive these algorithms, but all are based on data below approximately $20 \mathrm{~m} / \mathrm{s}$. Although these various algorithms produce comparable results in the parameter range for which they were developed, when extrapolated to wind speeds above $20 \mathrm{~m} / \mathrm{s}$ they yield very different results. In-

Copyright 1993 by the American Geophysical Union.

Paper number 93JC02117.

0148-0227/93/93JC-02117\$05.00 deed, there have been suggestions that ALT data may not be suitable for the determination of high wind speeds. [Witter and Chelton, 1991].

In this paper, an indirect technique is used to determine an approximate relationship between the Geosat ALT radar cross section and wind speed for values of $U_{10}$ ranging between 20 and $40 \mathrm{~m} / \mathrm{s}$. This is achieved by examining data from Geosat tracks which pass through the centers of mature tropical cyclones (or hurricanes or typhoons). The wellformed vortex motion of such storms makes it possible to use relatively simple mathematical models to predict the resulting wind field with reasonable accuracy. The model values of $U_{10}$ can then be used to form a synthetic calibration data set for high wind speeds.

\section{Existing Wind Speed Algorithms}

Satellite radar altimeters view the water surface at near normal incidence (nadir). At such angles, scattering occurs from the rough surface by specular reflection [Jackson et al., 1992]. As the surface roughness increases, the scattering increases and the power of the reflected radar pulse, as measured by $\sigma_{0}$, decreases. A convenient measure of the surface roughness is the mean squared surface slope,

$$
\left\langle s^{2}\right\rangle=\int F(\underline{k}) k^{2} d \underline{k}
$$

where $F(\underline{k})$ is the directional wavenumber spectrum and $\underline{k}$ is the wavenumber vector. The radar cross section $\sigma_{0}$ is approximately inversely related to $\left\langle s^{2}\right\rangle$ [Moore and Fung, 1979; Barrick and Swift, 1980; Chelton and McCabe, 1985]. In addition, for $U_{10}<20 \mathrm{~m} / \mathrm{s}$ there is an approximately linear relationship between $U_{10}$ and $\left\langle s^{2}\right\rangle$ [Cox and Munk, 1954; Haimbach and Wu, 1985; Hwang and Shemdin, 1988; Jackson et al., 1992]. Data are not available for higher wind speeds, but on the basis of the argument that the momentum flux from wind to waves should not exceed the wind stress, Plant [1982] has proposed an upper limit to the wave slope. Jackson et al. [1992] have expressed this limit in terms of 
mean squared slope as $\left\langle s^{2}\right\rangle<0.08$. The existence of such a limit, together with the approximately inverse relationship between $\sigma_{0}$ and $\left\langle s^{2}\right\rangle$ (ie., small errors in $\left\langle s^{2}\right\rangle$ result in large errors in the derived value of $U_{10}$ ), implies an upper limit to wind speeds at which ALT can provide useful data. At high wind speeds, however, enhanced white capping may lead to further scattering in a manner similar to that described by Banner and Fooks [1985]. Hence the upper limit to the wind speed at which reliable data can be obtained from ALT is unknown.

\subsection{Brown's Algorithm}

Brown et al. [1981] compared a total of 184 values of wind speed derived from buoy measurements with values of GEOS $3 \sigma_{0}$. The data were in the range from 1 to 18 $\mathrm{m} / \mathrm{s}$. The resulting algorithm, commonly called the Brown three-branch algorithm, is

$$
\begin{array}{ll}
U_{10}=\sum_{n=1}^{5} a_{n} W^{n} & W \leq 16 \mathrm{~m} / \mathrm{s} \\
U_{10}=W & W>16 \mathrm{~m} / \mathrm{s}
\end{array}
$$

where

$a_{1}=2.087799, a_{2}=-0.3649928, a_{3}=4.062421 \times 10^{-2}$, $a_{4}=-1.904952 \times 10^{-3}, a_{5}=3.288189 \times 10^{-5}$,

and

$$
W=\exp \left[\left(10^{-\left(0.21+\sigma_{0} / 10\right)}-B\right) / A\right]
$$

with $\sigma_{0}$ being the radar cross section expressed in decibels and

$A=0.080774, B=-0.124651: \sigma_{0}<10.12 \mathrm{~dB}$

$A=0.039893, B=-0.031996: 10.12 \mathrm{~dB} \leq \sigma_{0}<10.9 \mathrm{~dB}$

$A=0.01595, B=0.017215: \quad \sigma_{0} \geq 10.9 \mathrm{~dB}$

Because the GEOS 3 and Seasat missions overlapped, Fedor and Brown [1982] attempted to cross-calibrate the altimeters for the two satellites. They compared 14 simultaneous (within 1 hour) measurements from the two platforms and found that within the approximate wind speed range from 1 to $10 \mathrm{~m} / \mathrm{s}$, the Seasat ALT was $1.6 \mathrm{~dB}$ higher than the GEOS 3 ALT. Hence they concluded that the Brown et al. [1981] algorithm could also be applied to Seasat provided the Seasat values of $\sigma_{0}$ were firstly reduced by $1.6 \mathrm{~dB}$. This was then confirmed by comparison of Seasat ALT derived winds with a total of 87 buoy measurements in the range 1 to $12 \mathrm{~m} / \mathrm{s}$.

\subsection{Chelton and McCabe Algorithm}

Chelton and McCabe [1985] examined the full three months of ALT data from Seasat and represented it as a temporal average on a $2^{\circ}$ by $6^{\circ}$ grid. They concluded that the discontinuities in the Brown three-branch algorithm lead to an unrealistic multimode probability distribution of wind speeds. To formulate a smooth function, they compared spatial and temporal averages from Seasat ALT and SCATT. Although the regions of the sea surface imaged by ALT and SCATT differ by approximately $200 \mathrm{~km}$, Chelton and
$M c$ Cabe [1985] argued that the averaging process employed would ensure that errors due to this spatial separation would have zero mean. A total of 1947 averaged values were considered in the wind speed range 3 to $14 \mathrm{~m} / \mathrm{s}$. The resulting algorithm was

$$
U_{10}=0.943 \times 10^{\left[\left(\sigma_{0} / 10-G\right) / H\right]}
$$

where $G=1.502, H=-0.468, \sigma_{0}$ has units of decibels, and the factor of 0.943 has been included here to convert the original algorithm from $U_{19.5}$.

Chelton and $M c$ Cabe [1985] noted that there was an indication in their data that (3) overestimated $U_{10}$ at high winds (greater than $12 \mathrm{~m} / \mathrm{s}$ ) and that although (3) and (2) agreed well over the range of wind speeds for which data were available, they diverged significantly at high wind speeds.

\subsection{Goldhirsh and Dobson Algorithm}

In order to develop an algorithm for use with Geosat until more detailed calibration data became available, Goldhirsh and Dobson, [1985] reviewed the algorithms proposed by both Brown et al. [1981] and Chelton and McCabe [1985]. Rather than adopt the Chelton and McCabe [1985] algorithm, which is based on indirect measurements of wind speed from SCATT, they smoothed the Brown three-branch algorithm with a fifth-order polynomial.

$$
U_{10}=\sum_{n=0}^{5} a_{n} \sigma_{0}^{n}
$$

where $a_{0}=-15.383, a_{1}=16.077, a_{2}=-2.305, a_{3}=$ $9.896 \times 10^{-2}, a_{4}=1.8 \times 10^{-4}, a_{5}=-6.414 \times 10^{-5}$, and $\sigma_{0}$ has units of decibels. The relationship is valid only over the range from 2 to $18 \mathrm{~m} / \mathrm{s}$ for which the polynomial fit was applied.

\subsection{Chelton and Wentz Algorithm}

Chelton and Wentz [1986] pointed out that there were a number of weaknesses in the wind speed algorithm developed for Seasat by Chelton and McCabe [1985]. Principally, the SCATT wind speed algorithm was erroneous. They reanalysed the Seasat ALT and SCATT data and developed a new algorithm based on data in the wind speed range from 0 to $21 \mathrm{~m} / \mathrm{s}$. Their result was expressed in a tabular form and is reproduced in Table 1.

\subsection{Witter and Chelton Algorithm}

Witter and Chelton [1991] attempted to cross-calibrate Seasat and Geosat ALT data in order to develop a wind speed algorithm for Geosat. As noted earlier, there was no overlap between Seasat and Geosat. Hence this crosscalibration was achieved by matching the probability distributions from the two instruments. Witter and Chelton [1991] argued that such a process was valid since variations in such distributions between years would be minor. The results were again presented in a tabular form (reproduced in Table 1) covering the wind speed range between 0 and 20 $\mathrm{m} / \mathrm{s}$. 


\subsection{Comparison of Existing Algorithms}

Figure 1 shows a comparison of the various algorithms described in the preceding sections. There is reasonable agreement for wind speeds ranging from 3 to $15 \mathrm{~m} / \mathrm{s}$, the region for which the bulk of the data exits upon which the algorithms were based. At higher wind speeds the various

TABLE 1. ALT Wind Speed Algorithms of Chelton and Wentz [1986] and Witter and Chelton [1991]

$$
U_{10}, \mathrm{~m} / \mathrm{s}
$$

algorithms diverge widely. The fact that many of the algorithms have been developed using indirect techniques such as SCATT winds and the comparison of wind statistics between years clearly demonstrates the difficulty of obtaining such data, even at these relatively low wind speeds. Recent independent comparisons by Ebuchi et al. [1992] and Guillaume and Mognard [1992], however, confirm the performance of these algorithms at low to moderate wind speeds.

The possibility of obtaining buoy data to extend these relationships to higher wind speeds is most unlikely. The instrumentation problems under such extreme conditions are considerable. In addition, it is necessary to impose tight spatial and temporal tolerances between buoy and satellite measurements to avoid the introduction of significant errors [Brown et al., 1981]. Hence progress must rely on indirect means to determine the wind speeds for these severe conditions.

\section{The Tropical Cyclone Wind Field}

One indirect means of determining wind speed estimates for use in calibrating ALT data would be to use meteorological predictions of surface wind speeds. Witter and Chelton [1991] have already used meteorological predictions to support the theory that interannual variation in the probability distribution of winds is small. A statistical approach such as this has the advantage that unbiased errors in the predictions will have zero mean and hence will not influence the result. Applying such predictions to specific points, for comparison with instantaneous ALT values of $\sigma_{0}$, is likely to introduce large errors. Provided there are sufficient points, however, such errors should still be randomly distributed with zero mean.

One means of reducing such errors would be to consider only meteorological systems for which the wind field can be estimated with a reasonable degree of accuracy. An example

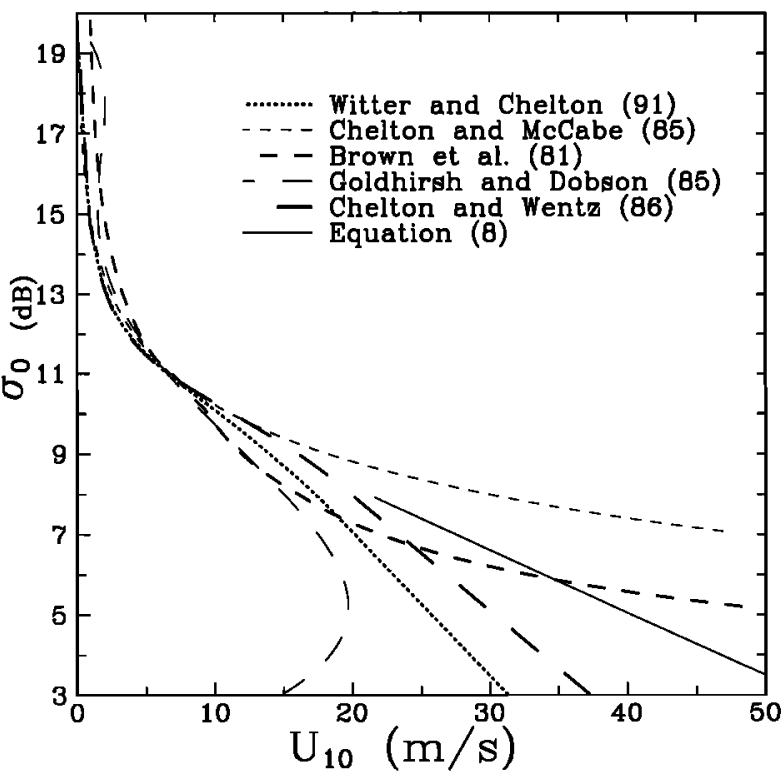

Fig. 1. A comparison of existing wind speed algorithms together with equation (8) (see section 4). All existing algorithms have been developed from data sets with $U_{10}<20 \mathrm{~m} / \mathrm{s}$, and hence the results shown for $U_{10}>20 \mathrm{~m} / \mathrm{s}$ represent extrapolations for these data. 
of this is the wind field within a mature tropical cyclone. The structure of the tropical cyclone wind field has been the subject of considerable research [Schloemer, 1954; Graham and Hudson, 1960; Smith, 1968; Gray and Shea, 1973; Shea and Gray, 1973; Simiu et al., 1976; Atkinson and Holliday, 1977; Wang, 1978; Holland, 1980]. The vortex-shaped wind fields in these well-formed systems are relatively similar from storm to storm. This similarity makes the prediction of the wind field more reliable than in other less organized meteorological systems. Nevertheless, there is variability between storms, and a full understanding of the tropical cyclone wind field is still lacking.

Holland [1980] has shown that the wind field can be represented in terms of a relatively simple parametric model. Following Holland [1980], the gradient wind can be expressed as

$$
U_{g}=\left[\frac{A B\left(p_{n}-p_{0}\right) \exp \left(-A / r^{B}\right)}{\rho r^{B}}+\frac{r^{2} f^{2}}{4}\right]^{0.5}-\frac{r f}{2}
$$

where $U_{g}$ is the gradient wind at radius $r$ from the center of the storm, $f$ is the Coriolis parameter, $\rho$ the air density, $p_{0}$ the central pressure, and $p_{n}$ the ambient atmospheric pressure far from the storm. The parameters $A$ and $B$ can be expressed in terms of the radius to maximum winds, $R$, as

$$
R=A^{1 / B}
$$

The dimensionless parameter $B$ defines the shape of the wind field with increasing distance from the center of the tropical cyclone. Increasing $B$ concentrates more of the pressure drop near $R$. Holland [1980] has shown that $B$ can be related to the central pressure $p_{0}$. A linear fit to his data yields

$$
B=1.5+\left(980-p_{0}\right) / 120
$$

where $p_{0}$ is expressed in hectopascals (or millibars).

Following Shea and Gray [1973], the radial winds are assumed to spiral in toward the center of the storm with a constant inflow angle of $25^{\circ}$. Also, a first-order asymmetry has been applied to the wind field by adding the cyclone forward speed $V_{f m}$ to the symmetric flow and rotating the maximum to an angle of $70^{\circ}$ to the direction of the cyclone forward motion (to the left in southern hemisphere and to the right in northern hemisphere). These modifications are consistent with the results of Shea and Gray [1973] and Shapiro [1983]. Naturally, there can be variability in all these parameters, particularly the angle to the maximum winds, which can vary significantly between storms [Shapiro, 1983]. The gradient wind velocity $U_{g}$ was reduced to $U_{10}$ (1-min. average) by the application of a factor of 0.8 [Powell, 1980]. Hence the full wind field is defined by the specification of the position of the center of the storm, the central pressure $p_{0}$, radius to maximum winds, $R$, and the direction and velocity of forward translation.

Figure 2 shows a typical example of the two-dimensional wind field generated by the model, together with the distri-

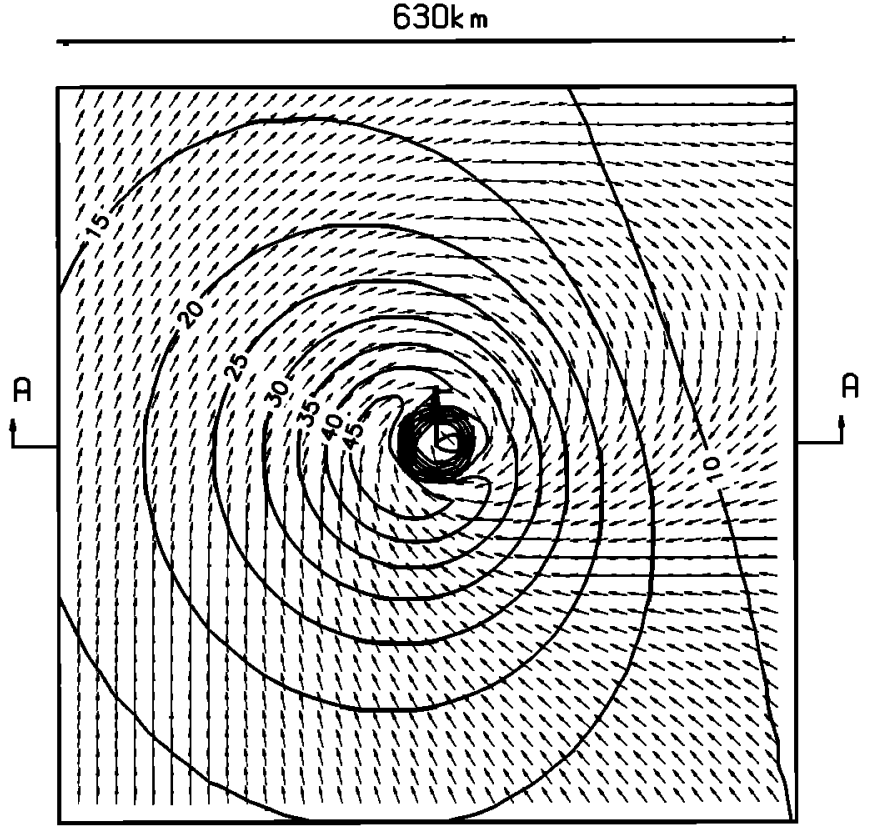

Fig. 2a. An example of the wind field generated by the Holland [1980] tropical cyclone model. The contours are of $U_{10}$ in units of meters per second. The vectors indicate the wind direction. The tropical cyclone shown has the following wind field parameters: $p_{0}=950 \mathrm{HPa}, V_{f m}=10 \mathrm{~m} / \mathrm{s}$, and $R=50 \mathrm{~km}$. The storm is propagating directly up the page as shown by the large arrow, whose base is located at the center of the storm.

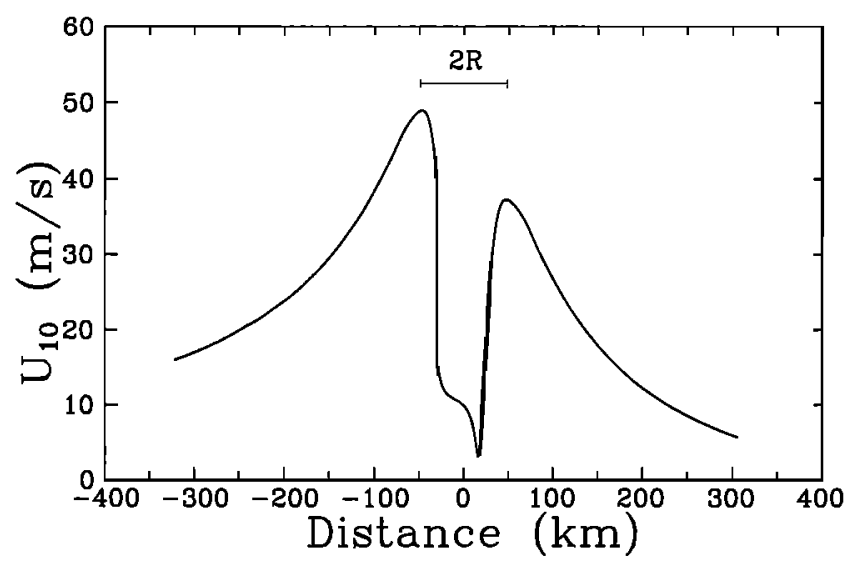

Fig. 2b. The wind speed profile through the center of the tropical cyclone shown in Figure $2 a$ alone the line AA. This is typical of the wind speed profile which would result for a satellite altimeter with a ground track corresponding to AA.

bution of wind speed along a line through the center of the storm. The case shown has a central pressure $p_{0}$ of $950 \mathrm{HPa}$, a velocity of forward movement $V_{f m}$ of $10 \mathrm{~m} / \mathrm{s}$, and a radius to maximum winds, $R$ of $50 \mathrm{~km}$. The asymmetric structure of the wind field is clear with the maximum wind occurring in the crescent-shaped region to the left of this southern hemisphere storm. The wind speed profile through the center of the storm (Figure $2 b$ ) shows the relatively calm eye of the tropical cyclone. The wind velocity increases rapidly to a maximum at a distance $R$ from the center before decaying in an approximately exponential manner with a further increase in distance. 
The model has been compared with recorded data by $H u b-$ bert et al. [1991] and extensively validated in a number of detailed studies for the oil industry on Australia's North-West Shelf [B. A. Harper, private communication, 1992). As part of these studies, data from 24 tropical cyclones that have occurred in this region have been compared with model wind fields. Generally, the model performs remarkably well, particularly for storms with relatively simple tracks and whose parameters do not vary rapidly. Model accuracy will be limited for two reasons. The first, is the model's inherent limitations in representing a possibly complex wind field by a relatively simple parametric form; the second, is the ability to accurately determine the model parameters defining the storm. To give an example of model performance, two cases from this extensive database are considered in Figure 3. The two storms considered here have been selected since their respective centers passed directly over anemometer stations and they both had relatively simple tracks. In both cases, the parameters used in the model were those provided

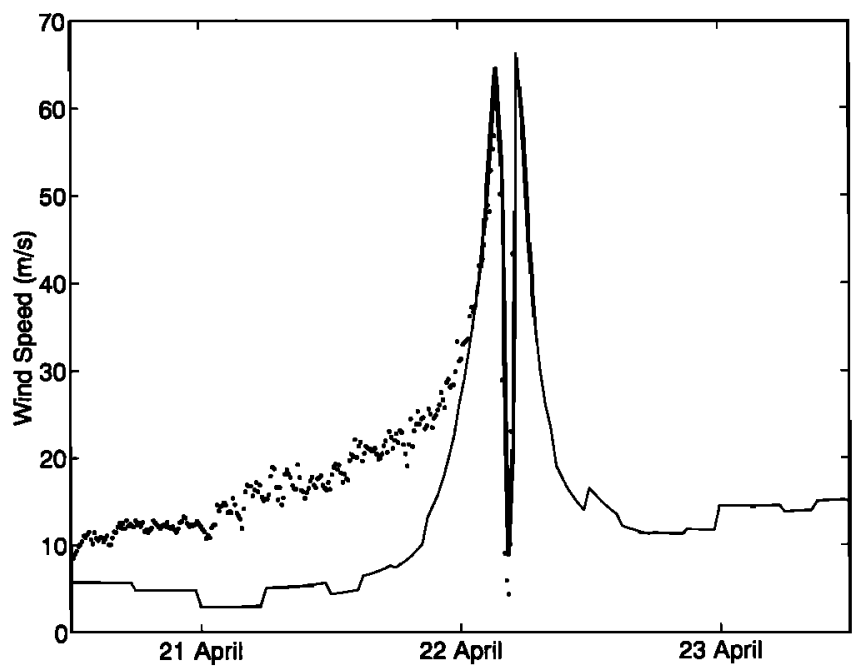

Fig. 3a. Comparison between recorded (dots) and model (solid line) values of $U_{10}$ at North Rankin A platform $\left(-19.58^{\circ} \mathrm{S}\right.$, $116.14^{\circ} \mathrm{E}$ ) during the passage of tropical cyclone Orson in 1989.

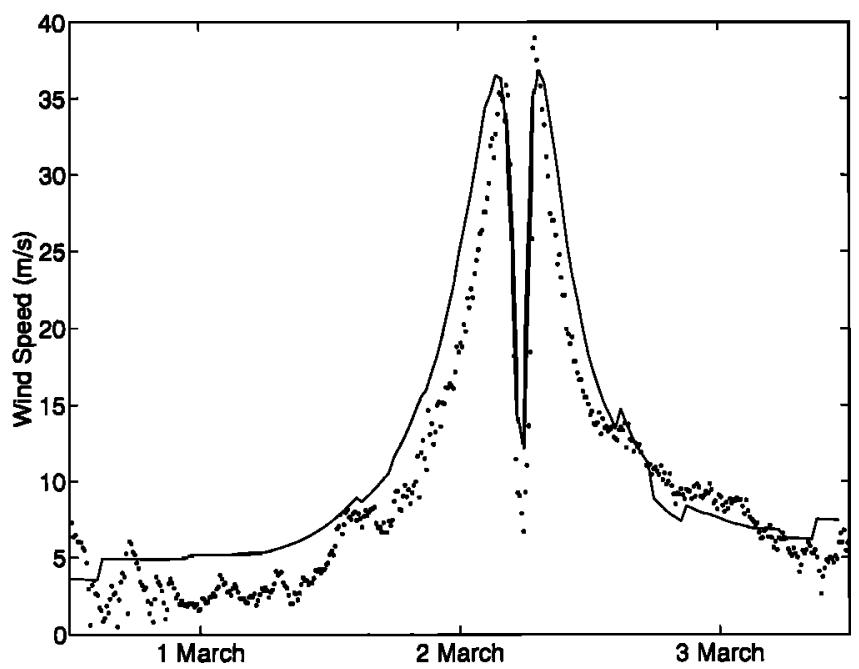

Fig. 3b. Comparison between recorded (dots) and model (solid line) values of $U_{10}$ at Barrow Island $\left(-20.82^{\circ} \mathrm{S}, 115.39^{\circ} \mathrm{E}\right)$ during the passage of tropical cyclone Ian in 1992. by the Australian Bureau of Meteorology, and no attempt has been made to optimize the agreement between model and data by altering these parameters.

Figure $3 a$ shows a comparison between the recorded and model winds at Woodside Offshore Petroleum's North Rankin A gas platform $\left(-19.58^{\circ} \mathrm{S}, 116.14^{\circ} \mathrm{E}\right)$ during the passage of tropical cyclone Orson in 1989. Tropical cyclone Orson is the most severe tropical cyclone to have occurred in the Australian region since reliable records have been kept (50 years). The storm had a minimum central pressure of $905 \mathrm{HPa}$ at $1030 \mathrm{UT}$ on April 22, 1989, when centered at $-18.35^{\circ} \mathrm{S}, 116.35^{\circ} \mathrm{E}$. Six hours later at $1630 \mathrm{UT}$ it passed over the North Rankin A platform with a central pressure of $906 \mathrm{HPa}$. The maximum wind speed recorded was $U_{10} \approx 63$ $\mathrm{m} / \mathrm{s}$. Unfortunately, shortly after the passage of the eye of the storm over the measurement location, the anemorneter failed. The agreement between model and data at the peak of the storm is very good. During the approach of the storm to the measurement location, the model significantly underestimates the wind speed. This can occur for a variety of reasons. The model considers only the influence of the tropical cyclone vortex, and hence any winds resulting from the background synoptic flow are ignored. As a result, the model could generally be expected to underestimate the wind speed when the storm is distant from the measurement location. In Figure $3 a$, however, it is also likely that the radius to maximum winds, $R$, has been underestimated during the approach of the storm, and possibly the parameter $B$ was too large.

Figure $3 b$ shows the comparison between model and recorded data at Barrow Island $\left(-20.82^{\circ} \mathrm{S}, 115.39^{\circ} \mathrm{E}\right)$ during the passage of tropical cyclone Ian in 1992. Tropical cyclone Ian was an intense tropical cyclone which reached a minimum central pressure of $930 \mathrm{HPa}$ at $0700 \mathrm{UT}$ on March 1,1992 , when located at $-16.37^{\circ} \mathrm{S}, 117.15^{\circ} \mathrm{E}$. Its intensity gradually decreased as it approached Barrow Island, passing over the anemometer site at 1830 UT on March 2, 1992, with a central pressure of $961 \mathrm{HPa}$. Both model and recorded data indicate a maximum wind velocity of $U_{10} \approx 38 \mathrm{~m} / \mathrm{s}$. The data show a more rapid rise and fall of wind speed during the passage of the storm, indicating the model storm is spatially larger than indicated by the data. This is probably due to an overestimation of the radius to maximum winds, $R$, which is generally difficult to estimate without additional information.

These results are indicative of the quality of the wind field predictions expected from the model. Differences do occur, and as a result, it is important to assess the magnitude of such errors and whether they introduce a bias into the results. Such an analysis is included in section 4.1 .

\section{THE $\sigma_{0}-U_{10}$ RELATIONSHIP FOR HIGH WIND SPEEDS}

The Australian Bureau of Meteorology, the U.S. National Oceanographic and Atmospheric Administration (NOAA), and the Joint Typhoon Warning Centre, Guam, provided data on the positions and wind field parameters of all tropical cyclones that occurred in their respective areas of interest during the period of the Geosat mission. When correlated against Geosat track information, approximately 1500 Geosat passes occurred within $1000 \mathrm{~km}$ of the center of a tropical cyclone. A total of 153 individual tropical cy- 
clones were represented within this database. Although the Holland [1980] wind field model has been shown to reproduce reasonably accurate tropical cyclone wind fields, it requires accurate estimates of the tropical cyclone parameters. Hence the database was heavily edited to remove storms for which the provided wind field parameters were fluctuating or for which the track changed direction rapidly. To ensure that there were no errors in the determination of the position of the storm centers, only storms for which the Geosat ground track passed through the calm eye of the storm were included. Such storms were determined by, first, examining only storms for which the reported position coincided with a Geosat ground track. Second, only storms for which the Geosat values of $\sigma_{0}$ showed a trend consistent with a rapid fall in wind speed in the eye of the storm were retained. This ensured that the central position of each of the storms was accurately determined. Further, provided that it is assumed that there is a monotonic relationship between $\sigma_{0}$ and $U_{10}$, the radius to maximum winds, $R$, can be determined from $\sigma_{0}$. That is, $R$ can be assumed to lie at the minimum value of $\sigma_{0}$ (maximum $U_{10}$ ), the center of the storm being at the maximum value of $\sigma_{0}$ (minimum $U_{10}$ ). The velocity and direction of forward movement were determined from successive fixes of the storm central position. As only storms with simple track geometries were included, errors in these parameters should be minimal. The central pressure $p_{0}$ was taken as the value provided by the relevant meteorological institute. The ALT values of significant wave height $H_{s}$ were, however, compared with predicted values from the wind wave prediction model of Young [1988] to ensure that the quoted central pressures were plausible.

The editing procedure described above reduced the data set to six passes of the satellite. The details of these storms are shown in Table 2. These passes represented a total of 1476 ALT values of $\sigma_{0}, 192$ of which had values less than $8 \mathrm{~dB}$ (indicating $U_{10}>20 \mathrm{~m} / \mathrm{s}$ based on the algorithm of Witter and Chelton, [1991]).

Figure 4 shows a scatter plot of the Geosat ALT $\sigma_{0}$ values against the corresponding values of $U_{10}$ derived from the Holland [1980] model for each of the passes. In addition, the Witter and Chelton [1991] result and a linear least squares fit to the portion of the data above $U_{10}=20 \mathrm{~m} / \mathrm{s}$ are shown. Although there is significant scatter, obvious trends are clear. For $U_{10}<20 \mathrm{~m} / \mathrm{s}$ the data falls below the Witter and Chelton [1991] result. As explained earlier, this occurs since these data are from regions far from the centers of the storms where the model could be expected to underpredict the actual wind speed due to its neglect of the synoptic background flow. This is particularly evident at the quite low wind speeds. At $20 \mathrm{~m} / \mathrm{s}$, the approximate upper limit of validity for the Witter and Chelton [1991] result, the agreement is quite good. The minimum velocity predicted by the model will be limited by the velocity of forward movement, which is simply added to the wind field. This minimum wind speed floor in the model is clearly evident at low wind speeds in Figure 4.

For wind speeds above $U_{10}=20 \mathrm{~m} / \mathrm{s}$, the model could be assumed to yield reasonable results, and a clear relationship is evident between $\sigma_{0}$ and $U_{10}$, despite considerable and not unexpected scatter. In the region where $U_{10}=15$ $25 \mathrm{~m} / \mathrm{s}$ there is enhanced scatter. Data from cyclone 2 are consistently low in this region and data from cyclone 4 are high. At higher wind speeds, data from these cyclones are once again consistent with the other cyclones. This presumably indicates either that the wind fields for these storms deviated from the form assumed by the model or that there was an error in one or more of the parameters specifying their respective wind fields. Although these data may appear anomalous, they have been retained in the subsequent analysis as there is no defensible reason for discarding them.

\subsection{Error Analysis}

The scatter observed in Figure 4 could have a number of sources, including errors in the determination of the tropical cyclone parameters, inadequacies in the Holland [1980] model, the accuracy of the satellite $\sigma_{0}$ values, and smallscale variability of the wind field. Provided these errors are randomly distributed about some mean, they will not bias the result, given sufficient data to form a good statistical estimate of the mean. Freilich and Dunbar [1993] have shown that in certain circumstances wind field estimate errors can introduce a net bias in the results. To determine whether this is the case in the present application requires a careful error analysis.

4.1.1. Tropical Cyclone Parameters. The Holland [1980] wind field model described in section 3 is fully defined by the specification of six parameters: the central pressure $p_{0}$; the profile shape parameter $B$; the radius to maximum winds $R$; the velocity of forward movement $V_{f m}$; the angle to maxi-

Table 2. Relevant Parameters of the Tropical Cyclones for Which Geosat Altimeter Ground Tracks Passed Through the Eye of Each Storm

\begin{tabular}{ccccc}
\hline Cyclone & Date & Time & Position & Central Pressure \\
& & UT & Latitude, Longitude, ${ }^{\circ}$ E & HPa \\
\hline \multirow{2}{*}{1} & March 3, 1987 & 0650 & $-19.38,194.24$ & 982 \\
2 & Jan. 9, 1988 & 1928 & $-10.87,169.85$ & 962 \\
3 & Jan. 9, 1988 & 1936 & $8.51,161.01$ & 968 \\
4 & Oct. 2, 1988 & 1628 & $14.55,130.91$ & 973 \\
5 & Feb. 25, 1989 & 1828 & $-19.80,74.65$ & 958 \\
6 & July 9,1989 & 1313 & $17.80,116.28$ & 991 \\
& & & &
\end{tabular}




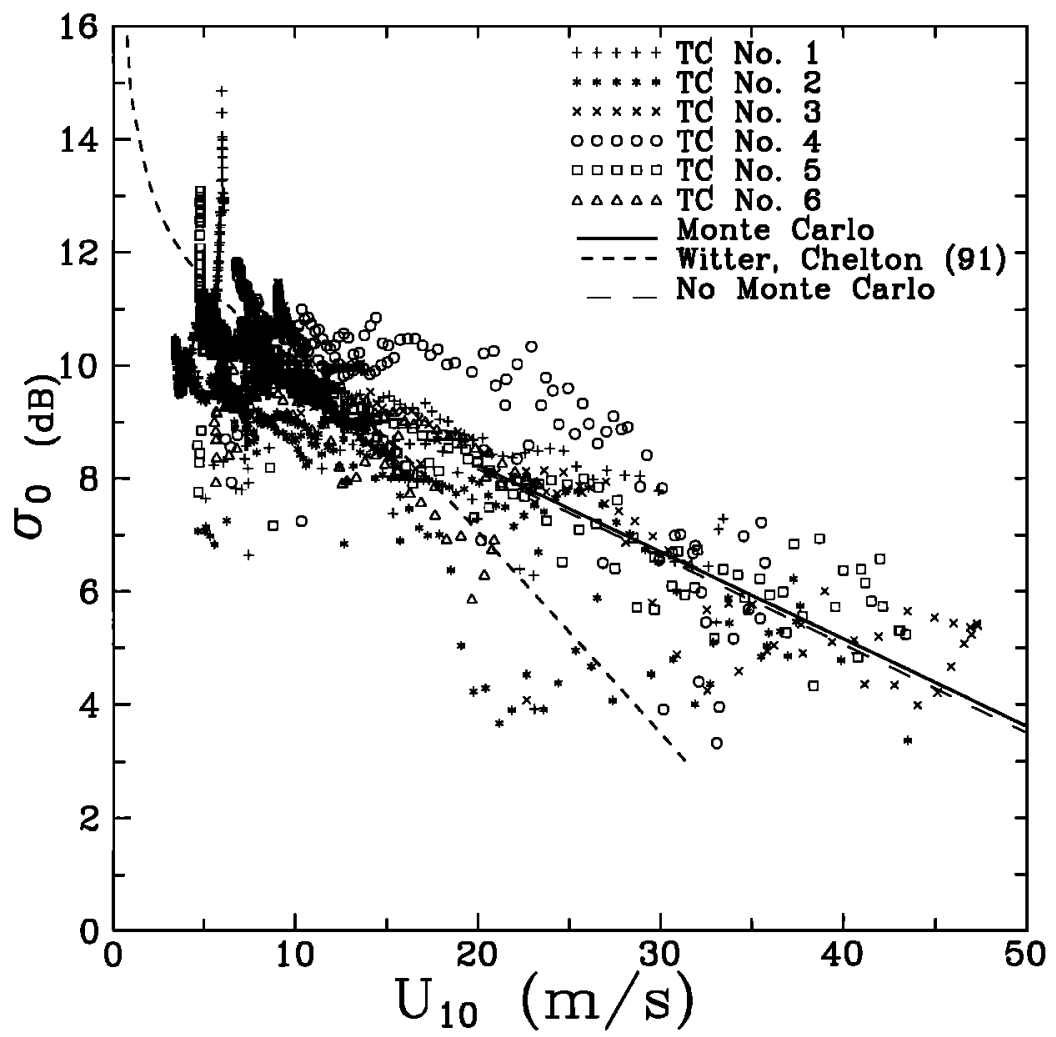

Fig. 4. A scatter plot of the Geosat altimeter radar cross section $\sigma_{0}$ versus wind speed for the passes through the six tropical cyclones (TC) described in Table 2. The algorithm of Witter and Chelton [1991] is shown as a comparison. Least squares linear fits to the data with $U_{10}>20 \mathrm{~m} / \mathrm{s}$ are also shown. The solid curve (equation (8)) represents the mean values of the Monte Carlo simulation; the dashed curve is the result if no Monte Carlo simulation is conducted (ie., mean wind field parameters used to determine $U_{10}$ ).

mum winds $\theta_{\max }$; and the direction of forward movement of the storm, $\theta_{3}$. Uncertainty as to the values of any of these parameters will lead to potential errors in the determination of the wind field. To assess the potential impact of such errors, an extensive Monte Carlo simulation was conducted.

In this analysis it was assumed that errors in $V_{f m}$ and $\theta_{3}$ would be minor. This is a reasonable assumption since only storms with simple tracks and for which the satellite passed through the eye of the storm were considered. Hence the track and forward motion of the storm were well defined. The other four parameters were assumed to be random variables distributed normally about their mean values for each storm. The adopted standard deviations of the normal probability distribution for each parameter are summarized in Table 3 .

The determination of these values of $\sigma_{n}$ is to some extent subjective; the rationale for the present choices is, however, described below. For variables which follow a normal probability distribution, $68 \%$ of values will lie within $\pm \sigma_{n}$ of the mean and $95 \%$ within $\pm 2 \sigma_{n}$. The radius to maximum winds, $R$ was determined from the minimum value of $\sigma_{0}$ recorded by the altimeter. Noise in the radar $\sigma_{0}$ values as well as the spatial resolution of the ALT footprint $(\approx 8 \mathrm{~km})$ could influence $R$. The footprint resolution could introduce a maximum error of approximately $4 \mathrm{~km}$. A value of $\sigma_{n}=5$ $\mathrm{km}$ appears consistent with the possible error. In contrast to $R$, which is reasonably accurately defined, the central pressure $p_{0}$ is often difficult to determine with precision for tropical cyclones which are distant from land. The adopted value of $\sigma_{n}=10 \mathrm{HPa}$ appears consistent with the precision of such estimates [Dvorak, 1975]. The parameter $B$ has been determined for the climatological relationship (7). As such, its precision is difficult to estimate. Holland [1980] has, however, shown that it must lie between 1.5 and 2.5 . On the basis of this possible range, a value of $\sigma_{n}=0.2$ was adopted. As mentioned earlier, there can be significant variability in the position of the maximum winds. To reflect this uncertainty, the quite large value of $\sigma_{n}=50^{\circ}$ was adopted for this parameter.

The intention of the Monte Carlo simulation is to determine whether these random errors introduce any net bias in the results and whether the observed scatter is consistent with such errors. Hence it is believed that the necessarily

Table 3. Assumed Values of Standard Deviation $\sigma_{n}$ Used for Each of the Tropical Cyclone Wind Field Parameters in the Monte Carlo Simulation

\begin{tabular}{cc}
\hline Parameter & $\begin{array}{c}\text { Standard Deviation } \\
\sigma_{n}\end{array}$ \\
\hline$p_{0}$ & $10 \mathrm{HPa}$ \\
$B$ & 0.2 \\
$R$ & $5 \mathrm{~km}$ \\
$\theta_{\max }$ & $50^{\circ}$ \\
\hline
\end{tabular}


subjective determination of the $\sigma_{n}$ values will not detract from these goals.

For each satellite value of $\sigma_{0}, 1000$ individual estimates of $U_{10}$ were generated by randomly selecting values for each of the wind field parameters. The randomly selected val- ues for each parameter satisfied the normal distribution for that parameter. The mean and 5 and 95 percentile points in the resulting distribution of $U_{10}$ were then selected for each value of $\sigma_{0}$. A sensitivity analysis was also conducted in which the 1000 realizations were increased to 5000 to en-
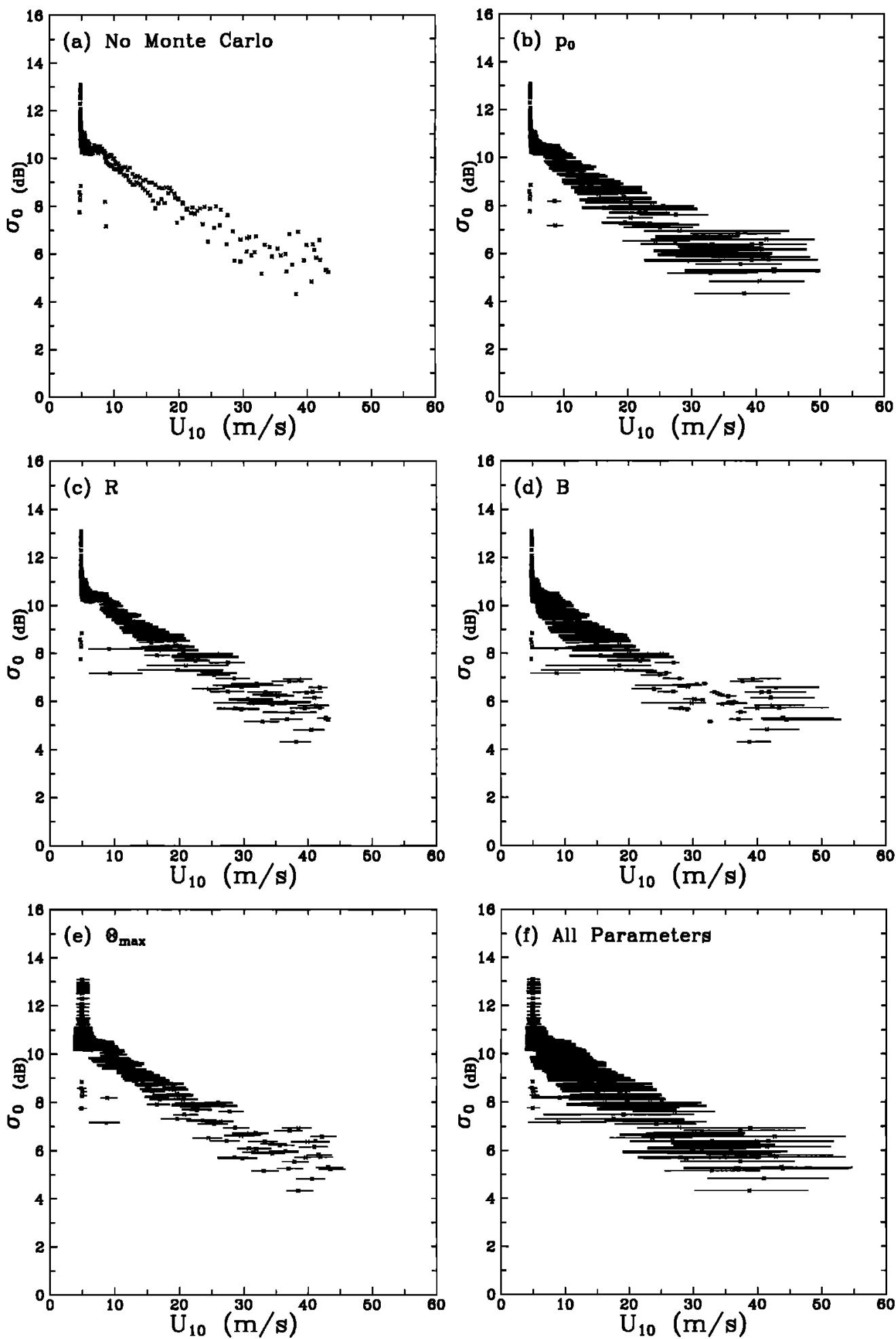

Fig. 5. Relationship between radar cross section $\sigma_{0}$ and model-inferred wind speed, $U_{10}$ for tropical cyclone 5. Each panel shows the resulting variability in $U_{10}$ when different model wind field parameters are regarded as statistical variables in the Monte Carlo simulation. The crosses show the mean values from the Monte Carlo simulations and the error bars are the $95 \%$ confidence limits. Results are shown when $(a)$ there is no Monte Carlo simulation (all parameters are considered constant), (b) only $p_{0}$ varies, $(c)$ only $R$ varies, $(d)$ only $B$ varies, (e) only $\theta_{\max }$ varies, $(f)$ all the above parameters vary simultaneously. 
sure sufficient points had been used to accurately define the resulting distributions. The results were, for practical purposes, identical.

In order to understand the sensitivity of the results to the assumed probability distributions, a further set of simulations were performed where only one of the parameters was allowed to vary at a time. The results for tropical cyclone 5 are shown in Figure 5. This figure shows the results when no Monte Carlo simulation was conducted, when the parameters were considered one at a time and, finally when all parameters were simultaneously included in the simulation. Figures $5 a-5 f$ show the mean as well as the 5 and 95 percentile points in the resulting $U_{10}$ distribution. Not surprisingly, the major influence is caused by $p_{0}$, particularly at the high wind speeds. These points are near the center of the storm where changes in the central pressure have most effect. The radius to maximum winds, $R$, and parameter $B$ have a smaller influence. Despite the large value of $\sigma_{n}$ selected for $\theta_{\max }$, this parameter introduces a relatively small amount of scatter in the results. It is the only parameter, however, that introduces variability to the low wind speed values obtained from points far from the storm center. When all parameters are combined, a trend consistent with the data shown in Figure 4 emerges. The confidence limits on the low wind speed data are relatively small. With increasing wind speed these confidence limits gradually increase.

4.1.2. Errors in $\sigma_{0}$. Another possible explanation for the observed scatter in the data are errors in the satellite derived values of $\sigma_{0}$. The Ims error for $\sigma_{0}$ is approximately $0.3-0.5$
$\mathrm{dB}$ [Dobson et al., 1987]. The reducing slope of the $\sigma_{0}-U_{10}$ relationship (Figure 4) means that errors in $\sigma_{0}$ are magnified with increasing $U_{10}$. Such errors would introduce no net bias into the derived relationship but would certainly account for some of the observed scatter.

An error source, however, which could introduce a net bias in the result would be the influence of atmospheric precipitation. The tropical cyclones considered in this study will almost certainly be accompanied by significant precipitation. Emery et al. [1990] have shown that atmospheric water vapor degrades the radar return and hence would reduce the observed values of $\sigma_{0}$. As well as influencing the radar transmission through the atmosphere, rainfall affects the water surface directly. Tsimplis and Thorpe [1989] show that rainfall tends to attenuate the high wavenumber components of the wave spectrum. This would result in less radar scattering and higher values of $\sigma_{0}$.

Of the two effects mentioned above, one acts to increase $\sigma_{0}$, the other to decrease it. The relative magnitudes of these two effects are difficult to quantify. It would be possible to make an estimate of the atmospheric water vapor for the tropical cyclones under consideration and hence correct $\sigma_{0}$. A correction for the direct effects of the rainfall on the water surface, however, would require a quantitative understanding of the high wavenumber attenuation caused by rainfall. As such a quantitative understanding is not available, no corrections for either of these effects have been attempted. The above discussion is intended to alert the reader to the possible consequences of such effects.

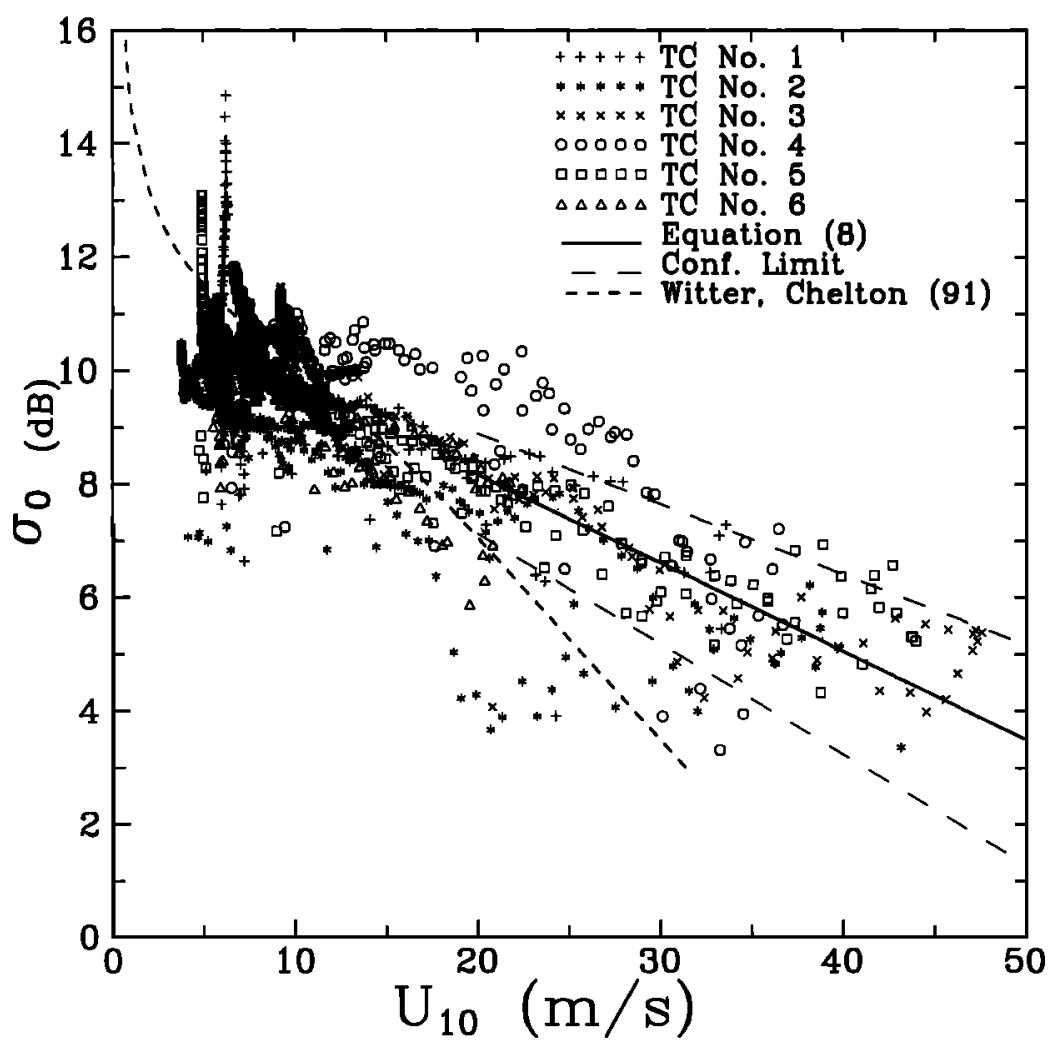

Fig. 6. Scatter plot as in Figure 4. The solid curve is the least squares fit to the mean values of the Monte Carlo simulation (equation (8)). The dashed curves represent a least squares approximation to the $95 \%$ confidence limits obtained from the Monte Carlo simulation. 


\section{2. $\sigma_{0}-U_{10}$ Algorithm}

To derive an approximate algorithm for high wind speeds, a linear least squares fit to the Monte Carlo results was performed for data in the region $U_{10}>20 \mathrm{~m} / \mathrm{s}$. The result is shown in Figure 4, indicating that the inclusion of the Monte Carlo analysis produces only a minor difference in the fit to the data. The best fit result is

$$
U_{10}=-6.4 \sigma_{0}+72
$$

where $U_{10}$ has units of meters per second and $\sigma_{0}$ has units of decibels. This result is shown in Figure 6, along with the $95 \%$ confidence limits obtained from the Monte Carlo analysis. These confidence limits are consistent with the observed data scatter. The magnitude of the scatter should be noted. As an example, for $\sigma_{0}=7 \mathrm{~dB}$, (8) yields $U_{10}=$ $27 \mathrm{~m} / \mathrm{s}$ but with $95 \%$ confidence limits between $20 \mathrm{~m} / \mathrm{s}$ and $35 \mathrm{~m} / \mathrm{s}$. In view of this scatter, there seems little validity in attempting anything other than a linear fit.

Jackson et al. [1992] show that the mean square slope $\left\langle s^{2}\right\rangle$ can be related to the radar nadir cross section by

$$
<s^{2}>=\rho_{n}^{\prime} / \sigma_{0}
$$

where $\rho_{n}^{\prime} \equiv 0.38$. Figure 7 shows the data of Figure 6 expressed in terms of $\left\langle s^{2}\right\rangle$ using (9), together with the $95 \%$ confidence limits on the result. The theoretical upper limit to $\left\langle s^{2}>\right.$ proposed by Plant [1982] and Jackson et al. [1992] is also shown. Except for the data outliers mentioned earlier (tropical cyclone 2), the data are generally below the Plant [1982] limit.

\section{Discussion AND CONCLUSIONS}

Existing wind speed algorithms for spaceborne altimeters have been developed from data within the range $U_{10}=0$ to $20 \mathrm{~m} / \mathrm{s}$. When extrapolated to higher wind speeds, the various algorithms yield divergent results. As the probability of obtaining data at wind speeds in excess of $20 \mathrm{~m} / \mathrm{s}$ during a satellite overpass is extremely low, progress in extending the wind speed algorithm to higher values requires an indirect means of determining the surface wind speed. One means of achieving such estimates would be to rely on meteorological predictions of wind speed. The success of such a process, however, is critically dependent on the accuracy of these predictions.

In an effort to reduce possible errors, this study examined Geosat passes that traversed the eyes of mature, stable tropical cyclones. These meteorological systems produce intense winds that, due to the nature of the well-organized pressure field, can be predicted with reasonable accuracy using analytical models. On the basis of the predicted wind fields for six tropical cyclones, an estimate of the Geosat ALT wind speed algorithm for wind speeds between 20 and $40 \mathrm{~m} / \mathrm{s}$ has been made.

An extensive Monte Carlo simulation was conducted to assess the consequences of uncertainty in the wind field estimates. The analysis indicates that wind field model errors introduce no net bias in the result. The Monte Carlo simulation does, however, explain a significant proportion of the observed scatter.

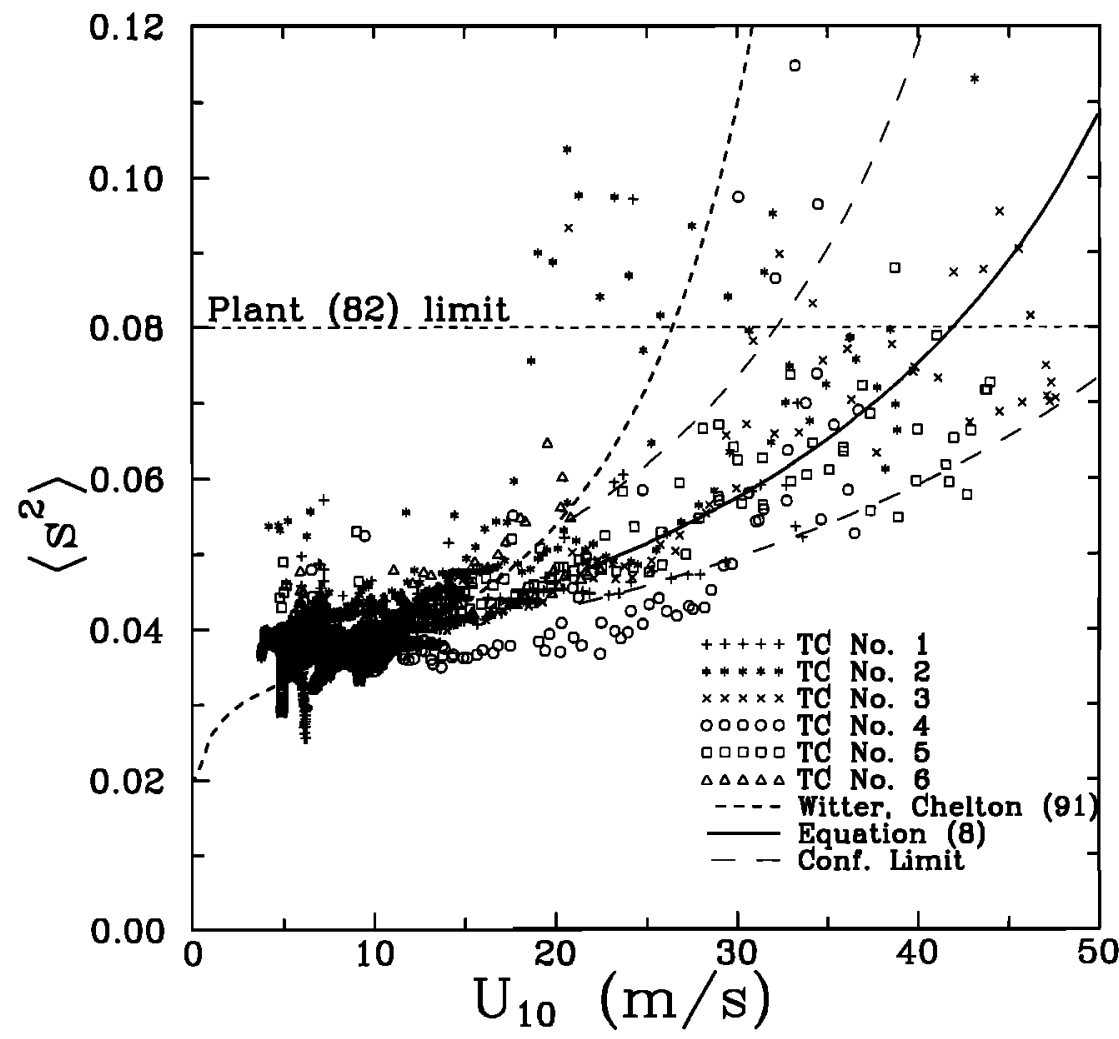

Fig. 7. A scatter plot of the mean squared slope as a function of wind speed. The data shown in Figure 6 were converted to mean squared slope using equation (9). The theoretical upper limit to mean squared slope proposed by Plant $[1982]$ is also shown together with the $95 \%$ confidence limits on the mean fit to the data. 
Owing to the significant data scatter and the inherent lack of accuracy of the altimeter at high wind speeds, the resulting wind speed algorithm is only an estimate. The results, however, show a clear trend within the scatter. The result is supported by the fact that at its lower limit of applicability $\left(U_{10}=20 \mathrm{~m} / \mathrm{s}\right)$, it is consistent with the higher quality low wind speed algorithms. A further check on the result can be made by determining the water surface mean squared slope corresponding to the measured radar cross section, for which there is a theoretical upper limit. The data generally lie below this limit, indicating that it has not saturated and contains information on the surface wind speed.

It is unlikely that altimeters can be used to obtain highly accurate wind speed predictions at high wind speeds. The results presented above show, however, that estimates of the wind speed can be made from altimeter data for wind speeds up to $40 \mathrm{~m} / \mathrm{s}$.

Acknowledgments. The wind speed data in Figure $3 a$ have been provided by Woodside Offshore Petroleum Pty. Ltd,, Perth, Western Australia. The author wishes to thank the Management of Woodside Offshore Petroleum Pty Ltd and the Joint Venture Participants in the North West Shelf Venture for approval to use and publish these data. The participants in the North West Shelf Venture are Woodside Petroleum Ltd. (through subsidiaries), Shell Development Australia Pty. Ltd,, BHP Petroleum (North West Shelf) Pty. Ltd., BP Developments Australia Ltd., Chevron Asiatic Limited, and Japan Australia LNG (MIMI) Pty. Ltd. The wind speed data in Figure $3 b$ were provided by WA Petroleum Pty. Ltd., (WAPET) Perth, Western Australia. The assistance of WAPET in providing access to these data is also gratefully acknowledged.

\section{REFERENCES}

Atkinson, G.D., and C.R. Holliday, Tropical cyclone minimum sea level pressure-maximum sustained wind relationship for western North Pacific, Mon. Weather Rev., 105, 421-427, 1977.

Banner, M.L., and E.H. Fooks, On the microwave reflectivity of small-scale breaking water waves, Proc. R. Soc. London Ser. A, 399, 93-109, 1985.

Barrick, D.E., and C.T. Swift, The Seasat microwave instruments in historical perspective, IEEE J. Oceanic Eng., OE5, 74-79, 1980.

Brown, G.S., H.R. Stanley, and N.A. Roy, The wind speed measurement capability of spaceborne radar altimetry, IEEE $J$. Oceanic Eng., OE6, 59-63, 1981.

Chelton, D.B., and P.J. McCabe, A review of satellite altimeter measurement of sea surface wind speed: With a proposed new algorithm, J. Geophys. Res., 90, 4707-4720, 1985.

Chelton, D.B., and F.J. Wentz, Further development of an improved altimeter wind speed algorithm, J. Geophys. Res., 91, 14,250-14,260, 1986.

Cox, C., and W. Munk, Statistics of the sea surface derived from sun glitter, J. Mar. Res., 13, 198-227, 1954.

Dobson, E., F. Monaldo, and J. Goldhirsh, Validation of Geosat Altimeter-derived wind speeds and significant wave heights using buoy data, $J$. Geophys. Res., 92, 10,719-10,731, 1987.

Dvorak, V.F., Tropical cyclone intensity analysis and forecasting from satellite imagery, Mon. Weather Rev., 103, 420-430, 1975.

Ebuchi, N., H. Kawamura, and Y. Toba, Growth of wind waves with fetch observed by the Geosat altimeter in the Japan Sea under Winter monsoon, J. Geophys. Res., 97, 809-819, 1992.

Emery, W.J, G.H. Born, D.G. Baldwind, and C.L. Norris, Satellite-derived water vapour corrections for Geosat altimetry, J. Geophys. Res., 95, 2953-2964, 1990.
Fedor, L.S., and G.S. Brown, Wave height and wind speed measurements from the Seasat radar altimeter, J. Geophys. Res., $87,3254-3260,1982$.

Freilich, M.H., and R.S. Dunbar, Derivation of satellite wind model functions using operational surface wind analysis: An altimeter experiment, J. Geophys. Res., 98, 14,633-14,649, 1993.

Goldhirsh, J., and E.B. Dobson, A recommended algorithm for the determination of ocean surface wind speed using a satelliteborne radar altimeter, Rep. JHU/APL SIR-85-U005, Johns Hopkins Univ., Appl. Phys. Lab., Laurel, Md, 1985.

Graham, H.E., and G.N. Hudson, Surface winds near the center of hurricanes (and other cyclones), NHRP Rep. 39, 200 pp. Govt. Print. Office, 1960.

Gray, W.M., and D.J. Shea, The hurricane's inner core region, II: Thermal stability and dynamic characteristics, J. Atmos. Sci., 30, 1565-1576, 1973.

Guillaume, A., and N.M. Mognard, A new method for the validation of altimeter-derived sea state parameters with results from wind and wave models, J. Geophys. Res., 97, 9705-9717, 1992.

Haimbach, S.P., and J. Wu, Field trials of an optical scanner for studying sea-surface fine structures, IEEE J. Oceanic Eng., OE $10,452-454,1985$.

Holland, G.J., An analytical model of the wind and pressure profiles in hurricanes, Mon. Weather Rev, 108, 1212-1218, 1980.

Hubbert, G.D., G.J. Holland, L.M. Leslie and M.J. Manton, A real-time storm-surge forecasting system for the Australian tropics, Weather Forecasting, 6, 86-97, 1991.

Hwang, P.A., and O.H. Shemdin, The dependence of sea surface slope on atmospheric stability and swell conditions, $J$. Geophys. Res., 93, 13,903-13,912, 1988.

Jackson, F.C., W.T. Walton and D.E. Hines, Sea surface mean

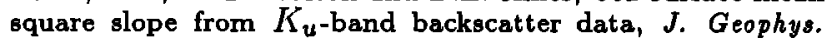
Res., 97, 11,411-11,427, 1992.

Moore, R.K., and A.K. Fung, Radar determination of winds at sea, Proc. IEEE, 67, 1504-1521, 1979.

Plant, W.J., A relationship between wind stress and wave slope, J. Geophys. Res., 87, 1961-1967, 1982.

Powell, M.D., Evaluations of diagnostic marine boundary layer models applied to hurricanes, Mon. Weather Rev., 108, 758$766,1980$.

Schloemer, R.W., Analysis and synthesis of hurricane wind patterns over Lake Okechobee, FL, Hydromet Rep. 31, 49 Pp., Govt. Print. Office, 1954.

Shapiro, L.J., The asymmetric boundary layer flow under a translating hurricane, J. Atmos. Sci., 40, 1984-1998, 1983.

Shea, D.J., and W.M. Gray, The hurricane's inner core region, I: Symmetric and asymmetric structure, J. Atmos. Sci., $\mathbf{3 0}$, 1544-1564, 1973

Simiu, E., V.C. Patel, and J.F. Nash, Mean speed profiles of hurricane winds, J. Eng. Mech. Div., Am. Soc. Civ. Eng., 102, 265-273, 1976.

Smith, R.K., The surface boundary layer of a hurricane, Tellus, 20, 473-484, 1968.

Tsimplis, M., and S.A. Thorpe, Wave damping by rain, Nature, $342,893-895,1989$.

Wang, G.C., Sea level pressure profile and gusts within a typhoon circulation, Mon. Weather Rev., 106, 954-960, 1978.

Witter, D.L., and D.B. Chelton, A Geosat altimeter wind speed algorithm and a method for altimeter wind speed algorithm development, J. Geophys. Res., 96, 8853-8860, 1991.

Young, I.R., A parametric hurricane wave prediction model, $J$. Waterw. Port Coastal Ocean Eng., Am. Soc. Civ. Eng., 114, 637-652, 1988.

I.R. Young, Department of Civil and Maritime Engineering, University College, University of New South Wales, Northcott Drive, Canberra, A.C.T. 2600, Australia.

(Received December 17, 1992; revised May 27, 1993; accepted July 7,1993 .) 